\title{
Uso de Sensoriamento Remoto e Geoprocessamento para estimativa de áreas vegetadas e não vegetadas nos bairros de maior crescimento em São Luís-MA,
}

\section{durante os anos de 2000 e 2010}

\author{
Use of Remote Sensing and Geoprocessing to estimate vegetated and non-vegetated areas in the \\ fastest growing neighborhoods in São Luís-MA, during the years 2000 and 2010 \\ Uso de Teledetección y Geoprocesamiento para estimar áreas con y sin vegetación en los barrios de \\ más rápido crecimiento en São Luís-MA, durante los años 2000 y 2010
}

Recebido: 13/04/2021 | Revisado: 20/04/2021 | Aceito: 21/04/2021 | Publicado: 06/05/2021

\author{
Ronald Costa Garcia \\ ORCID: https://orcid.org/0000-0002-8907-8693 \\ Universidade Federal do Maranhão, Brasil \\ E-mail: ronaldgarcia_@live.com \\ Rodrigo da Cruz de Araujo \\ ORCID: https://orcid.org/0000-0002-1937-3128 \\ Universidade Federal do Maranhão, Brasil \\ E-mail: araujo.rodrigo@ufma.br
}

\begin{abstract}
Resumo
Na cidade de São Luís do Maranhão houve um crescimento populacional de 17\% durante os anos de 2000 à 2010. O crescimento urbano decorrente de aumento populacional afeta a cobertura vegetal, em algumas áreas essa alteração pode ser positiva devido ao aumento da vegetação ou negativa devido a perda de vegetação. Uma vez que a expansão urbana afeta diretamente as áreas vegetadas faz-se interessante a realização de mapeamentos constantes da cobertura vegetal. Diante disso, o sensoriamento remoto e o geoprocessamento aliados a um Sistema de Informações Geográficas (SIG) podem ser alternativas viáveis para o estudo sobre o vigor vegetativo de determinadas regiões por meio do Índice por Diferença Normalizada (NDVI), como forma de estimar a alteração na vegetação decorrente da expansão urbana entre os anos de 2000 e 2010, na capital maranhense. Neste estudo, identificou-se os quinze bairros da cidade que obtiveram maior crescimento populacional, além disso os bairros foram classificados de acordo com os padrões de ocupações. A partir das imagens de satélites provenientes do sensoriamento remoto, aliadas com as técnicas de geoprocessamento foi possível estimar as áreas vegetadas e não vegetadas dos bairros de maior crescimento da cidade de São Luís-MA, nos anos de 2000 e 2010. Sete bairros apresentaram perdas de vegetação ao longo do período, outros sete apresentaram um aumento das áreas de vegetação e um bairro não apresentou variação.

Palavras-chave: Crescimento populacional; Sensoriamento remoto; Geoprocessamento.
\end{abstract}

\begin{abstract}
In the city of São Luís do Maranhão there was a population growth of $17 \%$ during the years 2000 to 2010 . The urban growth resulting from populational growth affects the vegetation cover, in some areas this change may be positive due to the increase in vegetation or negative due to the loss of vegetation. Since the urban expansion directly affects the vegetated areas, it is interesting to carry out a constant mapping of the vegetation cover. Therefore, remote sensing and geoprocessing combined with a Geographic Information System (GIS) can be viable alternatives for studying the vegetative vigor of certain regions through the Normalized Difference Index (NDVI), to estimate the change in the vegetation resulting from the urban expansion between the years 2000 and 2010, in the capital of Maranhão. In this study, we identified the fifteen neighborhoods in the city that achieved the highest population growth, in addition, the neighborhoods were classified according to occupancy patterns. From satellite images from remote sensing, combined with geoprocessing techniques, it was possible to estimate the vegetated and non-vegetated areas of the fastestgrowing neighborhoods in the city of São Luís-MA, in the years 2000 and 2010. Seven neighborhoods showed losses of vegetation over the period, another seven showed an increase in vegetation areas, and one neighborhood showed no variation.
\end{abstract}

Keywords: Population growth; Remote rense; Geoprocessing.

\section{Resumen}

En la ciudad de São Luís do Maranhão hubo un crecimiento poblacional del 17\% durante los años 2000 a 2010. El crecimiento urbano resultante del crecimiento poblacional afecta la cobertura vegetal, en algunas áreas este cambio 
puede ser positivo debido al aumento de la vegetación o negativo debido a la pérdida de vegetación. Dado que la expansión urbana afecta directamente a las áreas vegetadas, es interesante realizar un mapeo constante de la cobertura vegetal. Por tanto, la teledetección y el geoprocesamiento combinados con un Sistema de Información Geográfica (SIG) pueden ser alternativas viables para estudiar el vigor vegetativo de determinadas regiones a través del Índice de Diferencia Normalizada (NDVI), como una forma de estimar el cambio en la vegetación resultante de la urbanización. expansión entre los años 2000 y 2010, en la capital de Maranhão. En este estudio, identificamos los quince barrios de la ciudad que lograron el mayor crecimiento poblacional, además los barrios fueron clasificados según patrones de ocupación. A partir de imágenes satelitales de teledetección, combinadas con técnicas de geoprocesamiento, fue posible estimar las áreas con y sin vegetación de los barrios de más rápido crecimiento en la ciudad de São Luís-MA, en los años 2000 y 2010. Siete barrios mostraron pérdidas de vegetación. durante el período, otros siete mostraron un aumento en las áreas de vegetación y un barrio no mostró variación.

Palabras clave: Crecimiento de población; Teledetección; Geoprocesamiento.

\section{Introdução}

As construções de maneira geral podem causar grandes impactos no meio ambiente desde desflorestamentos, depósitos de resíduos descartados incorretamente, impermeabilização do solo, poluição atmosférica, entre outros. Assim, quando não há um controle dos números de edificações que estão sendo construídas, o problema ambiental tende a aumentar. (Leite, Pinheiro, \& Pamboukian, 2019)

Ocupações irregulares, na maioria das vezes, provocam mudanças no ecossistema local e na bacia hidrográfica, o que impacta no clima da região afetada por essas ocupações. Geralmente algumas residências se localizam em regiões próximos à cursos d'água, o que aumenta o número de casos de inundações e alagamentos. Outras residências se localizam em áreas de encostas, o que aumenta o número de casos de deslizamento de massa. Então, o problema ambiental torna-se também uma questão social (Louzeiro, 2018)

De acordo com Macedo (2005 apud Louzeiro, 2018) 28,3\% da população da capital do Maranhão vive em áreas de risco, que são caracterizadas por serem locais impróprios para se construir residências, sendo que esta porcentagem aumentou nos últimos anos devido ao crescimento populacional. De acordo com a Defesa Civil (2019), a cidade de São Luís possui cerca de 60 pontos de áreas de risco, e esse risco está associado a deslizamento de massas, inundações e alagamentos.

Para atenuar esses fatos, o planejamento urbano é direcionando pelo plano diretor da cidade, obrigatório para cidades com mais de 20 mil habitantes, o qual determina o uso e ocupação do solo e delimita as áreas onde podem ou não haver construções residenciais. No entanto, na prática não há uma verificação rígida por parte do poder público para verificar se as edificações estão sendo construídas em locais apropriados. Essa falta de fiscalização pode gerar, portanto, problemas ambientais como a retirada de cobertura vegetal, impermeabilização do solo, deslizamentos de terra, inundações, alagamentos, entre outros problemas.

De acordo com Ferreira (2002), apud Machado (2013), na ausência de planejamento urbano, a expansão urbana acelerada e não controlada das cidades acarreta em uma degradação socioespacial contínua, o que gera uma série de consequências negativas para a população influenciando na qualidade de vida dos habitantes e no espaço público.

Alves (2004) corrobora com o exposto anteriormente, afirmando que o crescimento urbano decorrente das aglomerações urbanas afeta também a cobertura do solo, pois o solo que antes permitia a infiltração das águas pluviais, agora se apresenta como uma superfície impermeável, o que gera um aumento da velocidade de escoamento superficial da água da chuva. E isso impacta diretamente nos sistemas de drenagem, já que os sistemas acabam não suportando esse aumento.

Nesse contexto, o sensoriamento remoto e o geoprocessamento podem ser excelentes ferramentas para as gestões municipais, estaduais e federais, pois permitem o monitoramento de grandes regiões, o que possibilita o mapeamento do uso e ocupação do solo e a quantificação dos elementos do espaço urbano e seus reflexos ambientais. (Meneses \& Almeida, 2012)

Diante disso, é de suma importância planejar o crescimento urbano e segundo Machado (2013) é necessário fazer mapeamentos constantes e extensivos para atualização da base de dados, principalmente de dados referentes à localização das 
áreas de risco, áreas ocupadas de maneira irregular, espaços públicos, zonas de proteção ambiental, perda de vegetação, expansão urbana, entre outros. De acordo com Freire (2010) apud Machado (2013) as alterações geográficas no espaço urbano requerem formas mais baratas de se atualizar e produzir informações espaciais de média e grande escala para fins de planejamento urbano, com isso o sensoriamento remoto e o geoprocessamento podem ser alternativas viáveis, tanto do ponto de vista econômico quanto do ponto de vista técnico, desde que a leitura e interpretação dos dados sejam feitas por pessoas capacitadas. (Almeida, 2010)

De acordo com Ponzoni, Shimabukuro e Kuplich (2012) a vegetação é muito afetada pelas ações antrópicas, e ao mesmo tempo é um indicador de qualidade ambiental de determinada área. Por conseguinte, analisar o estado da vegetação por meio do geoprocessamento, a partir de informações provenientes do sensoriamento remoto, pode ser uma maneira de compreender as causas dos problemas decorrentes das ocupações desordenadas e suas consequências como, por exemplo, a perda de vegetação.

A vegetação desempenha um papel fundamental no meio ambiente, pois quando a cobertura vegetal é retirada, para as construções, tais como pavimentações e edificações, o solo fica exposto e ocorre um maior escoamento superficial da água e, consequentemente, pode levar a feições erosivas no solo, acarretando problemas como alagamentos e deslizamentos de massa. (Nunes \& Roig, 2018).

De acordo com Louzeiro (2018) o crescimento populacional provoca cada vez mais alterações nas paisagens naturais. E estas alterações acabam por transformar as paisagens naturais em paisagens artificializadas. As ocupações em determinadas áreas como áreas próximas à cursos d'água e áreas de encosta, por exemplo, podem potencializar riscos tanto do ponto de vista ambiental, quanto riscos relacionados à integridade física e material das pessoas, que nesses locais residem.

Não é recomendável, portanto, a construção de residências nessas regiões, porque são áreas de risco, e muitas vezes são locais com topografia acentuada, com solos não estáveis ou são locais próximos a cursos d'água, e geralmente as construções não são acompanhadas por um responsável técnico habilitado, não havendo também um estudo preliminar da área. Além desses motivos, essas regiões podem sofrer com eventos naturais, tais como chuvas fortes o que aumenta as chances de alagamentos e deslizamentos de massa. (Leite, Pinheiro, \& Pamboukian, 2019). Porém, devido à alta valorização dos preços dos terrenos na cidade e o baixo poder aquisitivo de muitas pessoas, torna-se cada vez maior o número de habitantes em áreas de risco, pois há uma facilidade quanto ao acesso. (Louzeiro, 2018).

De acordo com Nóbrega (2007 apud Machado, 2013), o sensoriamento remoto pode oferecer ferramentas para a produção do mapeamento, análise e monitoramento dos sistemas urbanos. Dentro desse contexto, se pode verificar a existência de assentamentos em áreas de proteção ambiental permanente e a partir disso, formular políticas públicas para atender necessidades das pessoas que vivem nessa área.

Segundo dados do Instituto Brasileiro de Geografia e Estatística (IBGE) no município de São Luís do Maranhão houve um crescimento populacional de $17 \%$ entre os anos de 2000 e 2010. Segundo o último censo demográfico, realizado em 2010 pelo IBGE, a população da capital era de 1.014.837. E a estimativa da população em 2020 segundo o IBGE é de 1.108.975 habitantes.

As ocupações no solo da capital maranhense se intensificaram em algumas regiões, devido ao crescimento dos setores portuários, industrial e de construção civil. No entanto esse crescimento não foi direcionado por um sistema de planejamento urbano eficiente, o que possibilitou um aumento de ocupações espontâneas ao longo de várias regiões da cidade, e consequentemente a alteração na vegetação. (Silva \& Silva, 2016)

Diante disso, a presente pesquisa tem como objetivo estimar a alteração na vegetação dos bairros de maior crescimento populacional da cidade de São Luís-MA. Para a realização deste estudo identificou-se os 15 bairros da capital maranhense que apresentaram o maior crescimento populacional, através de pesquisas bibliográficas. E a partir de técnicas de 
geoprocessamento e sensoriamento remoto, por meio de um Sistema de Informação Geográfica (SIG) foi estimada às áreas vegetadas e não vegetadas de cada bairro analisado. Além disso, identificou-se quais foram as variações entre os anos de 2000 e 2010.

\section{Metodologia}

O presente trabalho é uma pesquisa exploratória de caráter quantitativo, pois visa estimar às áreas vegetadas e não vegetadas dos bairros de maior crescimento de São Luís. Pereira et al. (2018) afirmam que os métodos quantitativos visam o enfoque matemático, ou seja, a coleta de dados numéricos a respeito de determinado tema. Esses dados numéricos podem ser necessários para tomadas de decisões gerenciais por parte do poder público, ou servir de base referencial para outras pesquisas a serem desenvolvidas.

A coleta de dados e informações presentes no artigo aconteceu por meio de pesquisas bibliográficas, a respeito de temas relacionados ao crescimento urbano, sensoriamento remoto e geoprocessamento, realizadas através de artigos científicos, livros e sites. Ainda de acordo com Pereira et al. (2018), as pesquisas bibliográficas fornecem dados a respeito do tema estudado, e são muito relevantes para o desenvolvimento dos resultados e suas análises.

\section{Áreas de estudo}

A escolha das áreas de estudo consistiu-se em identificar os bairros que apresentaram maior crescimento populacional durante os anos de 2000 e 2010, além de classificá-los de acordo com o padrão de ocupação. A partir dessa seleção de bairros foi verificado se houve alteração nas áreas vegetadas e não vegetadas de cada um deles.

Na Tabela 1 são apresentados os 15 bairros que obtiveram os maiores crescimentos populacionais na cidade de São Luís-MA durante os anos de 2000 e 2010. Nesta tabela é apresentado o total de residentes de cada ano, o crescimento populacional entre os dois anos, a área de cada bairro segundo o Instituto da Cidade, Pesquisa e Planejamento Urbano e Rural INCID (2010), além do adensamento populacional dos dois anos. Segundo Rosário e Araújo (2019) o adensamento populacional é a relação entre a quantidade de residentes em determinada região dividida pela área dessa região. 
Tabela 1: Bairros de Maior Crescimento de São Luís entre 2000 e 2010.

\begin{tabular}{|c|c|c|c|c|c|c|}
\hline Bairros & $\begin{array}{l}\text { Residentes } \\
\text { (2000) }\end{array}$ & $\begin{array}{l}\text { Residentes } \\
\text { (2010) }\end{array}$ & $\begin{array}{l}\text { Crescimento } \\
\text { Populacional } \\
(\%)\end{array}$ & $\begin{array}{l}\text { Área } \\
\left(\mathbf{k m}^{2}\right)\end{array}$ & $\begin{array}{l}\text { Adensamento } \\
\qquad(2000)\end{array}$ & $\begin{array}{l}\text { Adensamento } \\
\qquad(2010)\end{array}$ \\
\hline Jardim América Central & 2339 & 4519 & 93,2 & 0,205768 & 11367,1708 & 21961,6267 \\
\hline Vila Airton Sena & 560 & 2304 & 311,43 & 0,106667 & 5249,9836 & 21599,9325 \\
\hline Salinas do Sacavém & 2243 & 4353 & 94,07 & 0,233202 & 9618,2709 & 18666,2207 \\
\hline Recanto dos Pássaros & 1179 & 2277 & 93,13 & 0,139615 & 8444,6514 & 16309,1358 \\
\hline São Raimundo & 3222 & 6708 & 108,19 & 0,663438 & 4856,5201 & 10110,9674 \\
\hline Jaracaty & 1334 & 3071 & 130,21 & 0,31838 & 4189,9617 & 9645,7064 \\
\hline Chácara Brasil & 953 & 2535 & 166 & 0,324064 & 2940,7771 & 7822,5289 \\
\hline $\begin{array}{l}\text { Jardim das Oliveiras/Ipem Turu/ } \\
\text { Residencial Turu/ } \\
\text { Vila União/ Recanto Fialho }\end{array}$ & 10405 & 31300 & 200,82 & 5,157628 & 2017,4002 & 6068,6812 \\
\hline Angelim & 5597 & 12823 & 129,1 & 2,231315 & 2508,3863 & 5746,8354 \\
\hline $\begin{array}{l}\text { Santa Rosa/Planalto Turu II/ } \\
\text { Vivendas do Turu }\end{array}$ & 3253 & 6510 & 100,12 & 1,691303 & 1923,3691 & 3849,1033 \\
\hline Jardim Eldorado & 1219 & 2327 & 90,89 & 0,814561 & 1496,5116 & 2856,7535 \\
\hline Vila Vitória & 1386 & 3609 & 160,39 & 1,782919 & 777,3769 & 2024,2086 \\
\hline Calhau/Recanto dos Nobres & 5858 & 11200 & 91,19 & 8,819412 & 664,2166 & 1269,9259 \\
\hline Ponta do Farol/São Marcos & 659 & 2754 & 317,91 & 2,48322 & 265,3812389 & 1109,043903 \\
\hline Pindorama & 436 & 848 & 94,5 & 1,33497 & 326,5990996 & 635,2202671 \\
\hline
\end{tabular}

Fonte: Rosário e Araújo (2019). Adaptado.

Ainda de acordo com Rosário e Araújo (2019), não existe uma delimitação exata dos limites dos bairros da capital maranhense. O IBGE utiliza um critério com base nos setores censitários, porém um mesmo setor pode abranger mais de um bairro, com isso esse critério não é tão adequado para se trabalhar com as áreas dos bairros. No entanto, o Instituto da Cidade, Pesquisa e Planejamento Urbano e Rural (INCID), organizou os bairros de São Luís-MA em distritos, e para este estudo considerou-se a delimitação proposta pelo INCID com base nos dados disponíveis pela Secretária de Saúde do Estado do Maranhão (SES) (Figura 1). 
Research, Society and Development, v. 10, n. 5, e27110515013, 2021

(CC BY 4.0) | ISSN 2525-3409 | DOI: http://dx.doi.org/10.33448/rsd-v10i5.15013

Figura 1: Mapa de distritos e bairros da cidade de São Luís-MA.

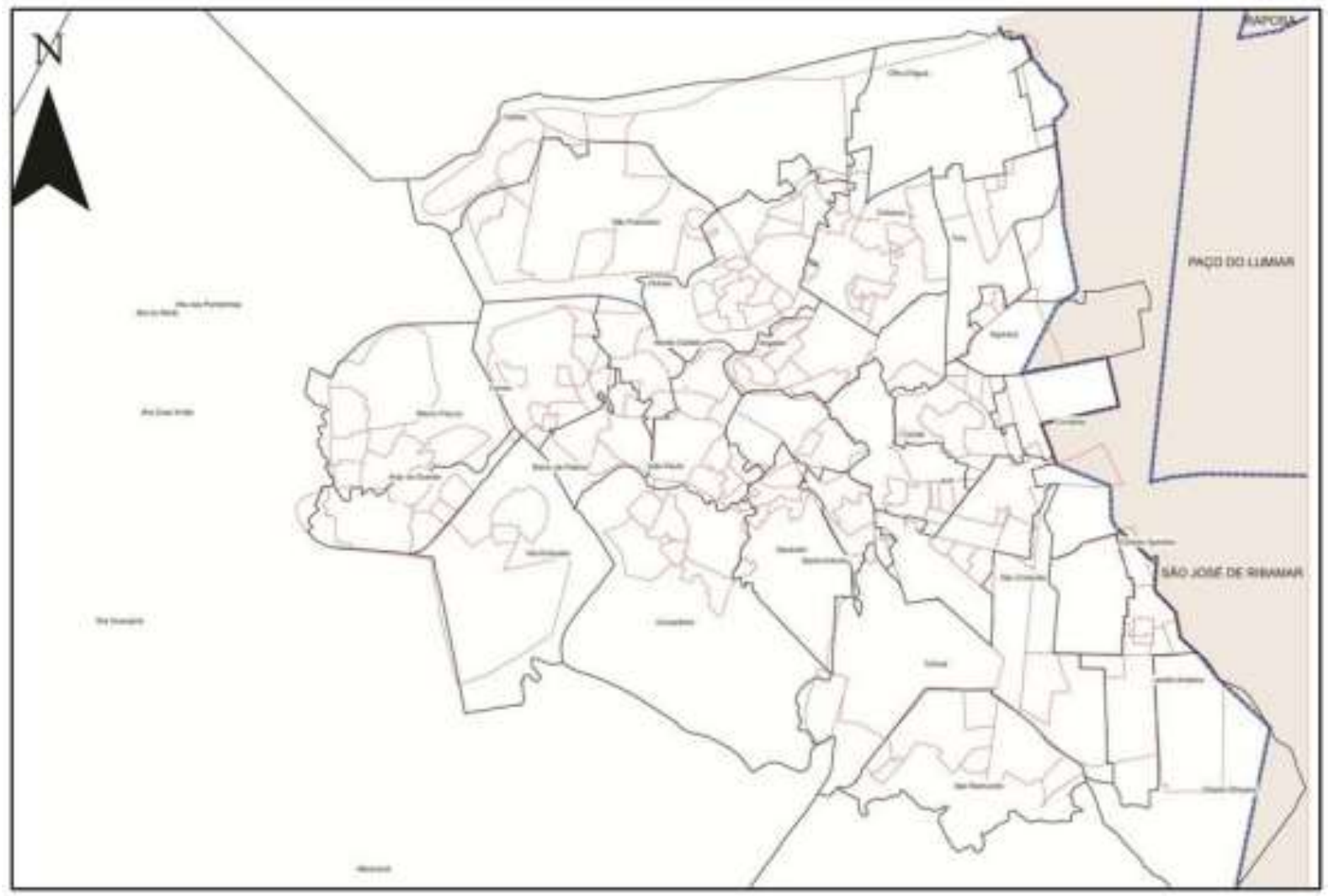

Fonte: INCID (2014), adaptado por Rosário e Araújo (2019).

Observa-se da Tabela 1 que os bairros Jardim América Central, Vila Airton Sena e Salinas do Sacavém apresentaram grandes taxas de adensamento, o que indica que são bairros, segundo Rosário e Araújo (2019), que não apresentam potencialidade para expansão de maneira adequada e sustentável. Vale ressaltar ainda que a alta taxa de adensamento pode refletir em maior alteração na vegetação durante esse período.

O outro critério a ser considerado para escolha das áreas a serem analisadas foi de que os bairros deveriam ser classificados de acordo com o padrão de ocupação (Figura 2). 
Figura 2: Mapa de padrões de ocupações de bairros da cidade de São Luís-MA.

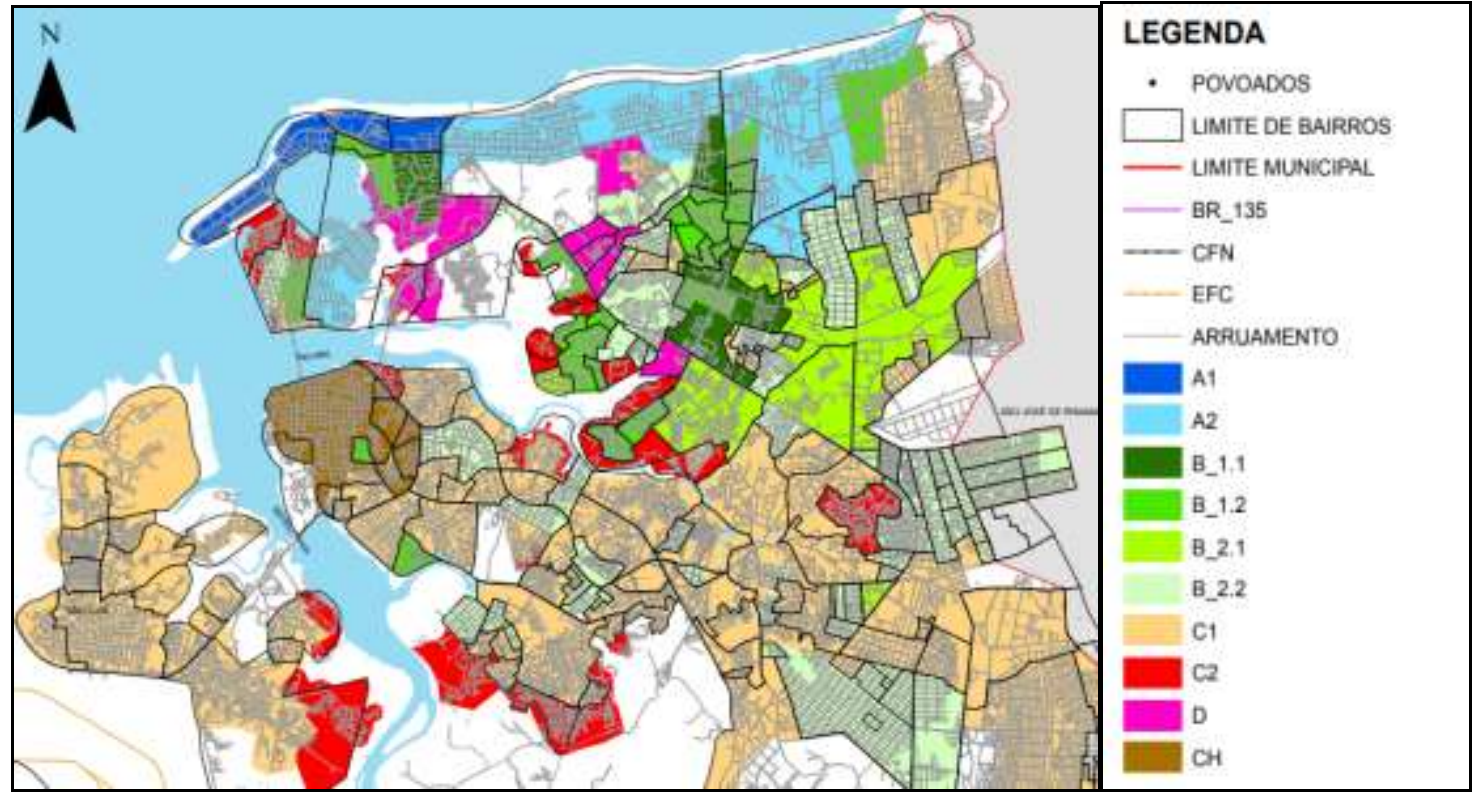

Fonte: INCID (2010). Adaptado.

Os padrões referidos no mapa sintetizam condições tais como dimensão média dos loteamentos na área, tipo de uso (residencial, comercial, industrial), e se ocupação foi regular ou irregular (Tabela 2).

Tabela 2: Legenda sucinta dos padrões de ocupação dos bairros de São Luís-MA.

\begin{tabular}{|c|c|}
\hline A1 & $\begin{array}{l}\text { Loteamentos regulares com média de áreas maiores que } 1000 \mathrm{~m}^{2} \text { com presença de conjuntos } \\
\text { residenciais multifamiliares verticais. }\end{array}$ \\
\hline A2 & $\begin{array}{l}\text { Loteamentos regulares com média de área entre } 450 \mathrm{~m}^{2} \text { a } 1000 \mathrm{~m}^{2} \text { com presenças de conjuntos } \\
\text { residenciais e predominância de residências unifamiliar }\end{array}$ \\
\hline B_1.1 & $\begin{array}{l}\text { Loteamentos regulares com média de áreas entre } 250 \mathrm{~m}^{2} \text { e } 360 \mathrm{~m}^{2} \text { com residências } \\
\text { predominantemente multifamiliar vertical. }\end{array}$ \\
\hline B_1.2 & $\begin{array}{l}\text { Loteamentos regulares com média de áreas entre } 250 \mathrm{~m}^{2} \text { e } 360 \mathrm{~m}^{2} \text { com residências } \\
\text { predominantemente unifamiliar }\end{array}$ \\
\hline B_2.1 e B_2.2 & $\begin{array}{l}\text { Loteamentos regulares com média de áreas entre } 250 \mathrm{~m}^{2} \text { e } 360 \mathrm{~m}^{2} \text { com residências } \\
\text { predominantemente unifamiliar e alguns conjuntos habitacionais verticais. }\end{array}$ \\
\hline C1 & Ocupações irregulares com loteamentos com média de áreas menores que 125 m². \\
\hline $\mathrm{C2}$ & Ocupações irregulares com loteamentos com média de áreas maiores que 125 m². \\
\hline D & Loteamentos para uso comercial e institucional. \\
\hline CH & Loteamentos com construções históricas. \\
\hline
\end{tabular}


A partir desse mapa e da legenda sucinta verificou-se quais seriam os bairros da Tabela 1 que possuíam ocupações irregulares. Utilizou-se ferramentas de geoprocessamento e sensoriamento remoto para estudo dessas áreas a partir do Índice por Diferença Normalizada (NDVI), como forma de estimar à alteração na vegetação decorrente da expansão urbana entre os anos de 2000 e 2010, na capital maranhense.

De acordo com Meneses e Almeida (2012) o índice NDVI já foi utilizado em vários estudos de cunho ambiental, para a determinação da alteração de vegetação de uma determinada região ao longo do tempo. Segundo Souza et al. (2017) o princípio do NDVI está relacionado à absorção da radiação na região espectral do vermelho pelas clorofilas, presentes nas células das plantas, e ao espalhamento ou reflectância da radiação na região do infravermelho próximo através das folhas das vegetações. Esses valores são expressos pela equação:

$$
N D V I=\frac{I v p-V}{I v p+V}
$$

Onde:

Ivp: valor de reflectância no infravermelho próximo.

V: valor de reflectância na banda do vermelho.

Segundo Meneses e Almeida (2012) essa equação gera valores entre -1 a 1. Valores maiores que zero indicam presença de vegetação e valores menores do que zero representam outros objetos como solo exposto, área urbana ou corpos hídricos. Para realizar a operação do índice NDVI é necessário um software SIG, e os valores de reflectância são representados pelas bandas dos sensores dos satélites. Com uso do SIG é possível fazer a distinção entre os diferentes materiais, identificar a área de urbanização e indicar o vigor vegetativo da região em análise. O vigor vegetativo é importante para discernir se houve um aumento ou diminuição da cobertura vegetal e pode indicar se essa vegetação está saudável ou não.

Foram utilizadas imagens do satélite TM/Landsat 5. Utilizou-se o software QGIS Desktop 3.18.1, que é um software SIG, para a elaboração de alguns mapas apresentados no artigo, na delimitação das áreas por polígonos e para o cálculo do índice NDVI utilizou-se a calculadora raster do QGIS, através da manipulação das bandas do satélite.

O QGIS é um software livre desenvolvido pela Open Source Geospatial Foundation (OSGEO), no qual se pode trabalhar com imagens raster, dados matriciais, vetoriais, e confecção de mapas temáticos a partir das informações georreferenciadas. (Leite, Pinheiro, \& Pamboukian, 2019).

Utilizou-se dados vetoriais em formato shapefile obtidos junto ao site do Instituto Brasileiro de Geografia e Estatísticas (IBGE), dados como limites dos municípios do estado do Maranhão. Para a confecção da delimitação das áreas de estudo, utilizou-se um arquivo em formato $\mathrm{kml}$ obtido junto ao portal eletrônico da Secretária de Saúde do Estado do Maranhão (SES), que contém os limites dos bairros da cidade de São Luís, os limites dos bairros foram estabelecidos pelo INCID (20100.

As cenas do TM/Landsat 5 foram obtidas no site U.S. Geological Survey (https://glovis.usgs.gov/), com cobertura de nuvens inferior a $10 \%$. As imagens foram utilizadas para o cálculo do NDVI e realizou-se um comparativo entre os anos de 2000 e 2010. As imagens passaram por um processo de correção de topo atmosférica utilizando um plugin do QGIS 3.18.1 chamado Semi-automatic classification plugin (SCP). De acordo com Diogo (2016) a correção de topo de atmosfera é essencial para análises utilizando imagens de satélite, pois as partículas presentes na atmosfera prejudicam o fluxo da radiação eletromagnética vinda do sol o que causa interferências nos resultados, a chamada interferência atmosférica.

De acordo com Pamboukian (2015) o SCP é um plugin, que permite a classificação semiautomática de imagens de satélites, nesse plugin também pode ser realizado o download de imagens além da correção de topo atmosférica utilizando o 
método DOS (Dark Object Subtraction) desenvolvido por Chavez (1988) criado para diminuir as interferências atmosféricas decorrente do espalhamento de partículas presentes na atmosfera. (Almeida et al., 2015)

O índice de vegetação é a integração de duas ou mais bandas espectrais, de acordo com algum procedimento prédeterminado, ou seja, está associado a uma operação aritmética entre bandas de satélites cuja finalidade é apresentar e realçar as características da vegetação como a biomassa, o vigor vegetativo e o índice de área foliar (Moreira, 2003).

Primeiramente utilizou-se as bandas espectrais do vermelho e do infravermelho próximo para calcular o índice NDVI, cada satélite possui bandas específicas para esse tipo de procedimento. Para o cálculo do NDVI das imagens do TM/Landsat 5 utilizou-se as bandas B03 (vermelho) e B04 (infravermelho próximo). Utilizou-se a calculadora raster do Qgis para calcular o índice. Logo após calculado o índice aplicou-se uma configuração de falsa cor na imagem, para evidenciar os alvos, já que o resultado do NDVI é dado em níveis de cinza.

O NDVI é uma imagem raster e após ser calculado para cada ano em estudo, transformou-se essa imagem em um dado vetorial, utilizando um algoritmo do Qgis, chamado binarização a partir de uma ferramenta chamada TheresholdVect, um plugin de manipulação de dados, no qual é possível transformar dados raster em dados vetoriais. A binarização das imagens, foi necessária para fazer a diferença entre a área vegetada da área não vegetada, pois esse processo gera um dado que possui somente dois valores, 1 e 0 , sendo 1 toda área vegetada e 0 a área não vegetada.

Após fazer a binarização das imagens, o resultado foi uma imagem raster, que foi transformada em uma imagem vetorizada, pois assim foi possível quantificar às áreas vegetadas e as áreas não vegetadas. Logo depois, realizou-se a união das camadas de limites dos bairros com a camada vetorizada gerada a partir da binarização. De acordo com Brinkhoff et al. (1994) a união de camadas tem como objetivo fazer a união de atribuições geométricas de diferentes feições desde que estas ocupem o mesmo local geográfico, ou seja, unir características espaciais de ambas as feições em uma camada única. Todas as camadas vetorizadas, passaram pelo processo de corrigir geometrias, com o objetivo de evitar erros no desenvolvimento do processo.

\section{Resultados e Discussão}

A partir do Mapa de Padrões de ocupação foi elaborada a Tabela 3 com os bairros e seus respectivos padrões de ocupações: 
Tabela 3: Classificação dos bairros de maior crescimento de acordo com os padrões de ocupações.

\begin{tabular}{|l|c|}
\hline Bairros & Padrão de Ocupação \\
\hline Jardim América Central & C1 \\
\hline Vila Airton Sena & C1 \\
\hline Salinas do Sacavém & C1 \\
\hline Recanto dos Pássaros & C1 \\
\hline São Raimundo & D e C2 \\
\hline Jaracaty & B_2.2 \\
\hline Chácara Brasil & B_2.2, B_2.1, C1 \\
\hline Jardim das Oliveiras/Turú/Ipem/Residencial Primavera Turú/ Vila & \\
\hline União Recanto Fialho & B_1.2 \\
\hline Angelim & B_2.2, B_2.1, C1 \\
\hline Santa Rosa/Planalto Turu II/Vivendas do Turu & B_2.2 \\
\hline Jardim Eldorado & C2 \\
\hline Vila Vitória & A2, D \\
\hline Calhau/Recanto dos Nobres & A1 \\
\hline Ponta do Farol/São Marcos & B_2.2 \\
\hline Pindorama & \\
\hline
\end{tabular}

Fonte: Autores (2021).

Como abordado anteriormente, os padrões de ocupações refletem as origens das ocupações segundo o INCID (2010), sendo os bairros C1 e C2 caracterizados por possuírem ocupações irregulares e o restante são os bairros caracterizados por possuírem ocupações regulares. Existem também bairros que possuem mais de um padrão de ocupação, sendo o bairro Jaracaty um exemplo, pois além de possuir ocupações irregulares, também é caracterizado por ser uma região com loteamentos de uso comercial e institucional.

A Figura 3 apresenta o mapa referente ao NDVI nos anos de 2000 e 2010. Como abordado anteriormente, quanto mais próximo de 1 maior é o vigor vegetativo, ou seja, presença de vegetação. 
Figura 3: Mapa do NDVI da cidade de São Luís-MA, gerado a partir das bandas 3 e 4 do satélite LANDSAT.

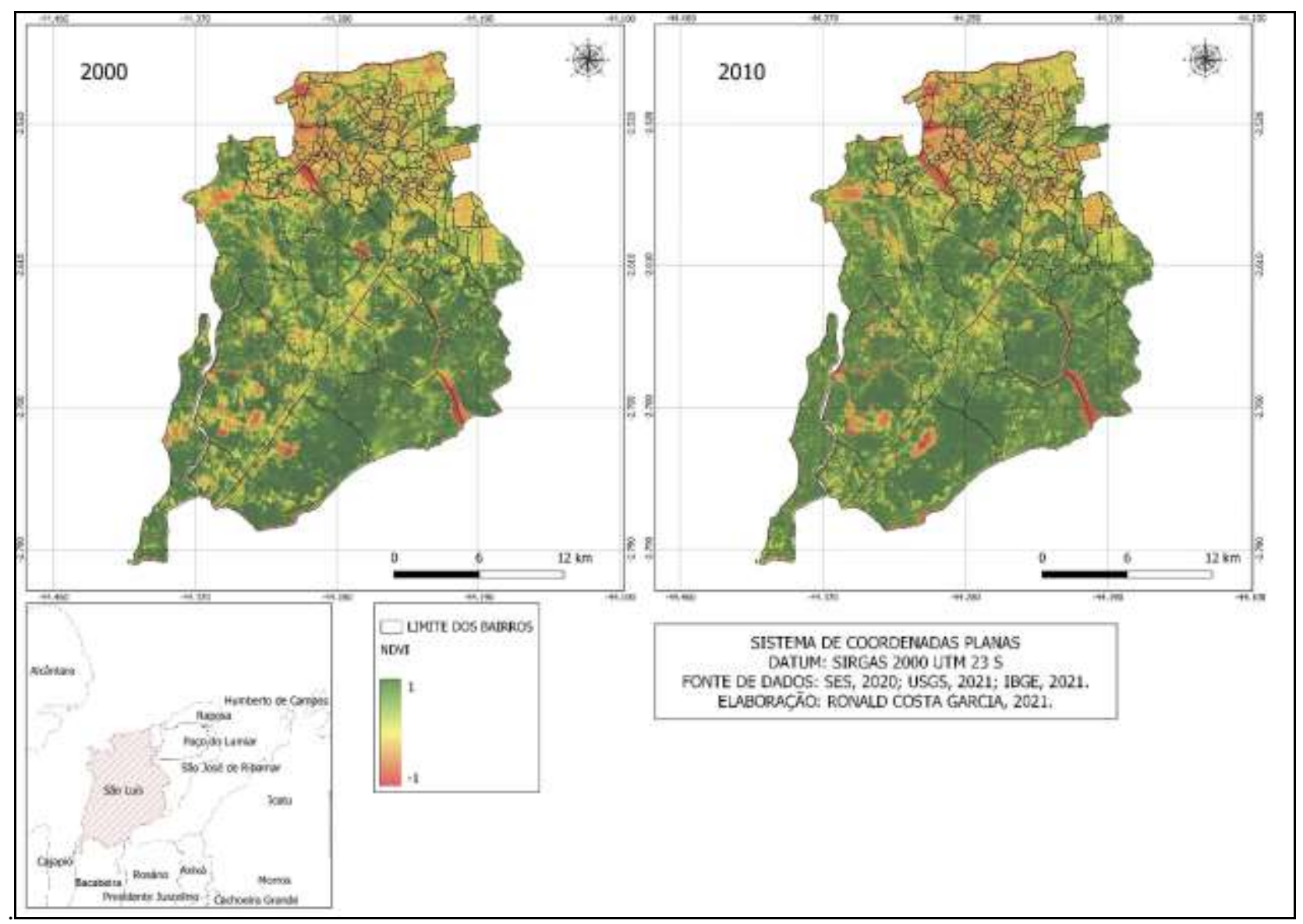

Fonte: Autores (2021).

Em alguns bairros podem ser visualizadas a diferença de NDVI nos dois anos, porém para se estimar a diferença de vegetação e de áreas não vegetadas nos dois períodos não basta somente realizar a análise visual: é necessário realizar a vetorização das imagens para quantificar as áreas de interesse. A Figura 4 apresenta o mapa temático das áreas não vegetadas no ano de 2000 e 2010, esse mapa foi confeccionado a partir da vetorização da imagem do NDVI por meio dos processos de binarização. 
Research, Society and Development, v. 10, n. 5, e27110515013, 2021

(CC BY 4.0) | ISSN 2525-3409 | DOI: http://dx.doi.org/10.33448/rsd-v10i5.15013

Figura 4: Mapa de Áreas não Vegetadas dos bairros da cidade de São Luís-MA.

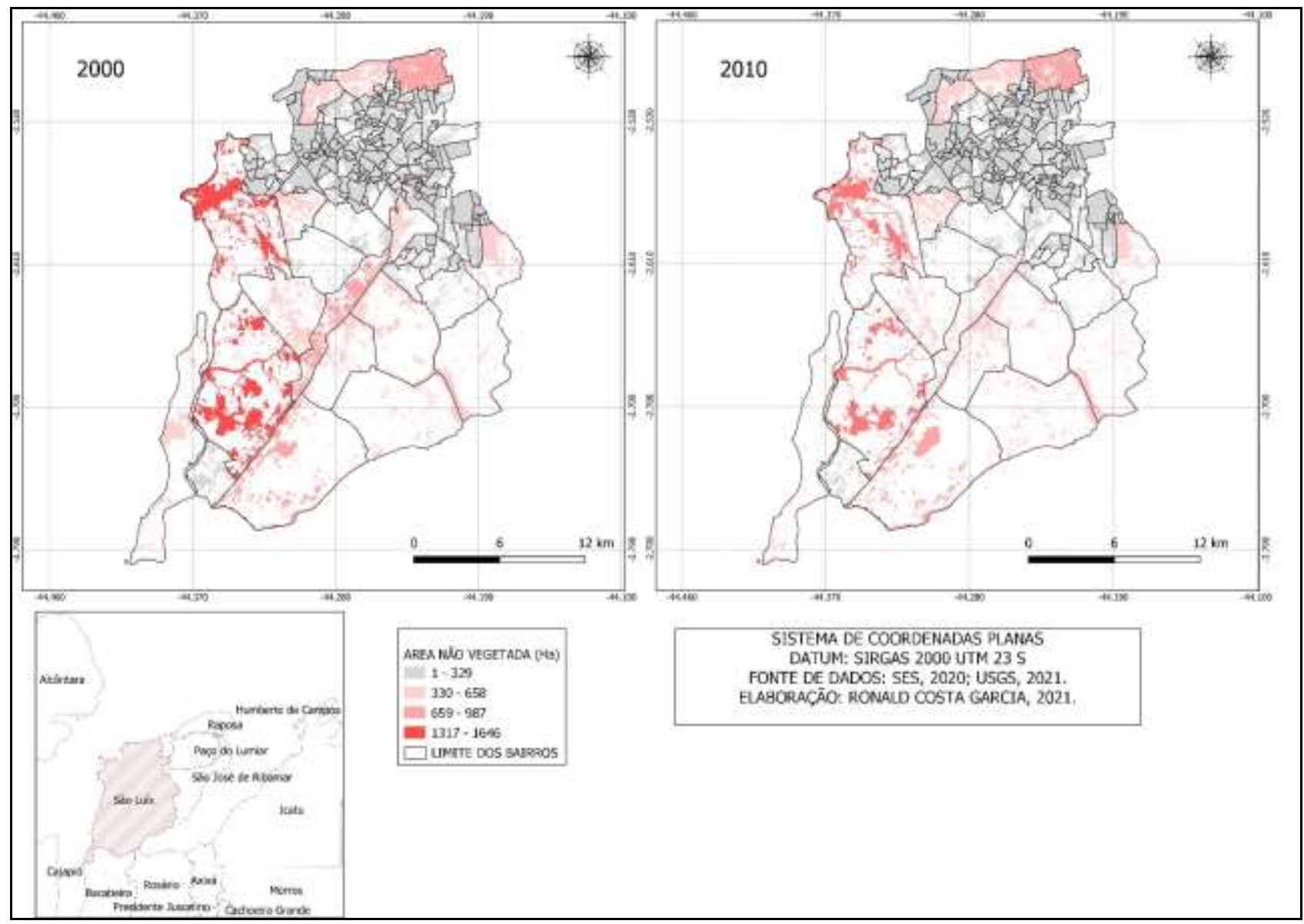

Fonte: Autores (2021).

Os resultados obtidos a partir da vetorização da imagem evidenciam a perda de vegetação em hectares (utilizou-se essa unidade de medidas para melhor visualização dos resultados). Nos 15 bairros analisados a área não vegetada nos dois anos ficou entre 1 (Ha) e 329 (Ha).

O mapa temático gerado, Figura 4, mostra que em algumas regiões houve o aumento de feições mais vermelhas, o que evidencia um crescimento de áreas não vegetadas. Essas áreas não vegetadas podem ser construções, corpos hídricos ou solo exposto. A Tabela 5 apresenta os resultados referentes às Áreas Não Vegetadas nos dois períodos. 
Tabela 5: Áreas não vegetadas dos Bairros de maior crescimento de São Luís-MA.

\begin{tabular}{|l|c|c|}
\hline \multicolumn{1}{|c|}{ BAIRROS } & $\begin{array}{c}\text { AREA NÃO } \\
\text { VEGETADA 2000 } \\
\text { (Ha) }\end{array}$ & $\begin{array}{c}\text { AREA NÃO } \\
\text { VEGETADA 2010 } \\
\text { (Ha) }\end{array}$ \\
\hline Jardim América Central & 18,292 & 18,119 \\
\hline Vila Airton Sena & 36,0067 & 19,1204 \\
\hline Salinas do Sacavém & 57,2884 & 42,9152 \\
\hline Recanto dos Pássaros & 14,422 & 14,4223 \\
\hline São Raimundo & 116,5686 & 109,605 \\
\hline Jaracaty & 36,1324 & 34,7026 \\
\hline Chácara Brasil & 54,8196 & 57,4965 \\
\hline Jardim das & 80,9861 & 83,9357 \\
\hline Oliveiras/Turú/Ipem/Residencial/Primavera Turú/ & & \\
\hline Vila União Recanto Fialho & & 130,8933 \\
\hline Angelim & 131,442 & 80,6983 \\
\hline Santa Rosa/Planalto Turu II/Vivendas do Turu & 107,9142 & 85,4022 \\
\hline Jardim Eldorado & 79,9459 & 22,7561 \\
\hline Vila Vitória & 58,8544 & 538,2654 \\
\hline Calhau/Recanto dos Nobres & 514,3926 & 99,4458 \\
\hline Ponta do Farol/São Marcos & 96,6438 & 87,094 \\
\hline Pindorama & 66,0165 & \\
\hline & & \\
\hline
\end{tabular}

Fonte: Autores (2021).

Percebe-se que em alguns bairros houve uma diminuição dos valores de Áreas não vegetadas entre os dois anos, isso pode estar relacionado com a presenças de nuvens na imagem de 2000, ou então como afirmam Meneses e Almeida (2012) os sensores orbitais sofrem com interferências geométricas devido ao posicionamento do sensor, instabilidade dos eixos da plataforma, curvatura da terra e campo de visada. Por meio da ferramenta de correção geométrica do SIG Qgis é possível diminuir esses ruídos, porém não os eliminar por completo.

Além dos ruídos relacionados com as interferências decorrentes da geometria ou interferências atmosféricas, vale destacar que alguns bairros como o Calhau/Recanto dos Nobres, que tiveram um crescimento populacional de 91,19\%, também tiveram um crescimento relacionado à área não vegetada e segundo o INCID (2010) este bairro é caracterizado como um bairro de categoria A2 e D, ou seja, possuí loteamentos entre $450 \mathrm{~m}^{2}$ e $1000 \mathrm{~m}^{2}$ além de ser uma região de classe alta e média alta com presença de vários condomínios residenciais e estabelecimentos comerciais, o que também contribuiu para o aumento das áreas não vegetadas.

A Tabela 6 apresenta as áreas vegetadas nos dois períodos além da variação na vegetação dos bairros de maior crescimento da cidade de São Luís, em alguns bairros ocorreram a perda de vegetação (variação negativa) e em outros bairros ocorreu uma alteração de vegetação positiva, ou seja, um ganho de vegetação. 
Tabela 6: Áreas vegetadas e alteração na vegetação nos Bairros de maior crescimento de São Luís-MA.

\begin{tabular}{|c|c|c|c|}
\hline BAIRROS & $\begin{array}{l}\text { AREA } \\
\text { VEGETADA } \\
2000 \text { (Ha) }\end{array}$ & $\begin{array}{c}\text { AREA } \\
\text { VEGETADA } \\
2010(\text { Ha) }\end{array}$ & $\begin{array}{l}\text { VARIAÇÃO } \\
\text { DE } \\
\text { VEGETAÇÃO } \\
\text { (Ha) }\end{array}$ \\
\hline Jardim América Central & 0,0111 & 0,1912 & 0,1801 \\
\hline Vila Airton Sena & 67,7809 & 84,6672 & 16,8863 \\
\hline Salinas do Sacavém & 85,7839 & 100,1571 & 14,3732 \\
\hline Recanto dos Pássaros & 0,0003 & 0 & $-0,0003$ \\
\hline São Raimundo & 35,522 & 42,4856 & 6,9636 \\
\hline Jaracaty & 18,069 & 19,4988 & 1,4298 \\
\hline Chácara Brasil & 8,8279 & 6,1511 & $-2,6768$ \\
\hline $\begin{array}{l}\text { Jardim das } \\
\text { Oliveiras/Turú/Ipem/Residencial/Primavera } \\
\text { Turú/ Vila União Recanto Fialho }\end{array}$ & 20,0147 & 17,0652 & $-2,9495$ \\
\hline Angelim & 82,9864 & 61,9089 & $-21,0775$ \\
\hline Santa Rosa/Planalto Turu II/Vivendas do Turu & 65,6027 & 92,6953 & 27,0926 \\
\hline Jardim Eldorado & 13,2752 & 7,8189 & $-5,4563$ \\
\hline Vila Vitória & 25,2596 & 61,358 & 36,0984 \\
\hline Calhau/Recanto dos Nobres & 233,8103 & 209,9375 & $-23,8728$ \\
\hline Ponta do Farol/São Marcos & 7,395 & 4,5929 & $-2,8021$ \\
\hline Pindorama & 82,9864 & 61,9089 & $-21,0775$ \\
\hline
\end{tabular}

Fonte: Autores (2021).

O bairro que obteve maior perda de vegetação foi o Calhau/Recanto dos Nobres, e como abordado anteriormente foi o bairro que apresentou maior crescimento de áreas não vegetadas, o que pode estar relacionado diretamente ao crescimento urbano nessa região decorrente da construção de condomínios residenciais e estabelecimentos comerciais. Dentre os bairros de categoria C2, bairros que contém ocupações irregulares, a maior perda de vegetação foi no bairro Pindorama o que pode também estar associado às ações antrópicas nessa região. O bairro Recanto dos Pássaros apresentou uma variação muito pequena de vegetação entre o período de 2000 a 2010, além disso, não apresentou variação de áreas não vegetadas.

O bairro Ponta do Farol/São Marcos apresentou uma perda de vegetação de 2,80 (ha) e isto pode estar relacionado ao aumento do número de condomínios presentes na região entre os anos de 2000 e 2010. Como afirma Coelho e Sales (2017) de 2004 a 2010 houve a construção de alguns condomínios residenciais nessa região.

O ganho de vegetação é apenas referente ao intervalo de 2000 a 2010, a variação na vegetação ao longo dos anos pode ser estimada se forem realizados outros estudos. Vale ressaltar que o aumento relativo de vegetação em alguns bairros pode estar diretamente relacionado às ações antrópicas, ou seja, pode ter acontecido que no ano mais antigo uma determinada área estava sem a presença da vegetação para a construção de residências, por exemplo, e com o passar dos anos as residências foram construídas e pode ter havido um crescimento de vegetação no quintal das casas.

O bairro Vila Vitória, que apresentou o maior ganho de vegetação entre os anos de 2000 e 2010 é um bairro que tem como classificação C2, que é um bairro caracterizado por possuir ocupações irregulares. Esse ganho de vegetação pode estar 
ligado diretamente às ações antrópicas, pois como abordado anteriormente, quando o satélite capturou imagens dessa área em 2000 pode ter ocorrido que alguns pontos não tivessem vegetação, ou então que a vegetação estivesse com o vigor vegetativo baixo e com o passar dos anos essa vegetação foi se desenvolvendo e foi captada no ano de 2010.

Outro ponto que pode ser considerado para a apresentação dos resultados referentes aos valores das áreas de vegetação e não vegetação é que os sensores possuem uma limitação quanto à resolução espacial, no caso do LANDSAT 5 a resolução é de 30 metros, o que segundo Meneses e Almeida (2012) significa que o menor objeto que se consegue identificar através de imagens desse satélite deve possuir $30 \mathrm{~m}$ x 30m, que é o tamanho do pixel e isso pode impactar os resultados obtidos, pois quando é realizado o processo de vetorização da imagem NDVI para a quantificação da feição seja ela área vegetada ou não, acaba ocorrendo um agrupamento das feições, por exemplo uma construção menor do que $30 \mathrm{~m}$ x $30 \mathrm{~m}$ pode ser agrupada como um objeto vegetado se a feição predominante for de área vegetada, o mesmo pode ocorrer para algumas vegetações que por ventura estão inseridas em uma área predominantemente não vegetada.

\section{Considerações Finais}

A maioria dos bairros quinze bairros, que apresentaram maior crescimento populacional na cidade de São Luís-MA, entre os anos de 2000 a 2010 obtiveram alterações na vegetação, sete apresentaram perda de vegetação, outros sete apresentaram um relativo ganho de vegetação e um bairro, o Recanto dos Pássaros, não teve alteração.

Sem as ferramentas de sensoriamento remoto, geoprocessamento e o SIG seria difícil estimar esses valores, mesmo com as interferências geométricas e interferências atmosféricas, minimizadas por através do SIG, foi possível realizar um mapeamento e um levantamento de dados referentes aos impactos na vegetação decorrente do crescimento populacional. Essas ferramentas proporcionaram quantificar às áreas de vegetação e não vegetação, o que pode auxiliar os gestores municipais a formularem políticas públicas referentes à preservação do meio ambiente além de ter dados quantitativos à respeitos das áreas antropizadas.

Portanto, é necessário fazer um mapeamento constante para o monitoramento das áreas dos bairros, como forma de conhecer melhor o espaço e as consequências decorrentes da expansão urbana. Este trabalho considerou somente os anos de 2000 e 2010, porém o mapeamento constante é justamente estudar as variações em outros anos, mas é claro comparando imagens provenientes de um mesmo sensor, para evitar mais ainda as interferências geométricas.

Neste sentido, este estudo pode ser utilizado como referência para desenvolvimento de pesquisas similares, podendose sugerir como estudos pesquisas utilizando sensores de satélites com resolução espacial maior, comparação entre anos mais recentes e anos mais antigos, realização estudos semelhantes em outras regiões da cidade de São Luís-MA, ou em outras cidades, além de servir como base para a elaboração de novas metodologias para a análise de áreas vegetadas e não vegetadas.

\section{Referências}

Almeida, C. M. (2010) Aplicação dos sistemas de sensoriamento remoto por imagens e o planejamento urbano regional. Arq.Urb, (3), 98-123. https://revistaarqurb.com.br/arqurb/article/view/120/106

Almeida, R. V., Araújo, M. D. D. O. G. D., Silva, A. C. D. S., \& Senna, J. A. D. (2015). Comparação dos Métodos de Correção Atmosférica: ”6S” e "DOS” processadas em dados do sensor TM/Landsat 5 e correspondentes a região de ocorrência da turfeira P-d-F. Anais XVII Simpósio Brasileiro de Sensoriamento Remoto - SBSR, João Pessoa-PB.

Alves, C. A (2004). Estimativa da área impermeável dentro da bacia do Arroio. Diluvio (Porto alegre - RS) através de técnicas de sensoriamento remoto e geoprocessamento. http://www.ufrgs.br/arroiodiluvio/conteudo-antigo/copy_of_sobre-o-arroio diluvio/estiamtivadaarea.pdf.

Brinkhoff, T., Kriegel, H. P., Schneider, R., \& Bernhard, S. (1994). Multi-Step Processing of Spatial Joins. ACM SIGMOD Record. 23. 10.1145/191839.191880.https://www.researchgate.net/publication/33030235_Multi-Step_Processing_of_Spatial_Joins 
Research, Society and Development, v. 10, n. 5, e27110515013, 2021

(CC BY 4.0) | ISSN 2525-3409 | DOI: http://dx.doi.org/10.33448/rsd-v10i5.15013

Diogo, R. F. (2016). Avaliação de Metodologias de correção da reflectância do topo da atmosfera para Landsat 8 Oli. Universidade Tecnológica Federal do Paraná. Campo Mourão-PR: http://repositorio.utfpr.edu.br/jspui/handle/1/7003

Defesa Civil de São Luís - MA (2019). Pontos de risco de São Luís. São Luís.

IBGE (2021). Instituto Brasileiro E Geografia E Estatística. Cidades. http://www.ibge.gov.br

INCID. (2010) Instituto da Cidade, Pesquisa e Planejamento Urbano e Rural. https://www.agenciasaoluis.com.br/site/arquivodacidade/2239

Leite, G. T. D., Pinheiro, R. Z. G., \& Pamboukian, S. V. D. (2019). Monitoramento de áreas de risco com a utilização de técnicas de geoprocessamento. Revista Mackenzie de Engenharia e Computação, 19(1), 28-47. São Paulo-SP.

Louzeiro, A. D. S. (2018) Vulnerabilidade e risco de movimento de massa no município de São Luís - MA (Brasil). https://repositorio.ufrn.br/jspui/bitstream/123456789/25405/1/Vulnerabilidaderiscom ovimento_Louzeiro_2018.pdf.

Machado, C. A S. (2013) Técnicas de sensoriamento remoto para identificação de áreas de concentração de polos geradores de viagens. https://www.teses.usp.br/teses/disponiveis/3/3138/tde-14052014-152928/pt-br.php

Meneses, P. M., \& Almeida, T. D. (2012). Introdução ao processamento de imagens de Sensoriamento remoto. http://www.cnpq.br/documents/10157/56b578c4-0fd5-4b9f-b82a-e9693e4f69d8

Moreira, A. M. (2003). Fundamentos do Sensoriamento Remoto e Metodologias de Aplicação. Editora UFV, 2a Ed., Viçosa MG.

Nunes, F. F., \& Roig, H. L (2014). Análise e mapeamento do uso e ocupação do solo da bacia do Alto do Descoberto, DF/GO, por meio de classificação automática baseada em regras e lógica nebulosa. Revista Árvore. http://dx.doi.org/10.1590/0100-67622015000100003.

$\begin{array}{llll}\text { Pamboukian, } & \text { P. } & \text { D. } & \text { (2015). }\end{array}$ https://www.mackenzie.br/fileadmin/OLD/62/ARQUIVOS/PUBLIC/user_upload/_imported/fileadmin/LABGEO/Curso/09._Aula_09/0901._Classificacao_su pervisionada.pdf

Pereira, A. S., Shitsuka, D. M., Parreira, F. J., \& Shitsuka, R. (2018). Metodologia da pesquisa científica. Editora UAB/NTE/UFSM. Santa Maria-RS

Ponzoni, F. J., Shimabukuro, Y. E., \& Kuplich, T. M (2012) Sensoriamento remoto no estudo da vegetação. Oficina de Textos, (2 ${ }^{\mathrm{a}}$ Ed,) São José dos Campos-SP

Rosário, R. C., \& Araújo, R. C. (2019). Estudo da expansão urbana da cidade de São Luís-MA. Revista Engenharia e Tecnologia. https://www.revistas2.uepg.br

Secretária de Saúde do Estado do Maranhão. (2021). https://www.saude.ma.gov.br/

Silva, J. S., \& Silva, R. M. (2016). Mapeamento e comparação entre índices de vegetação utilizando imagem OLI/Landsat 8 na bacia do Rio Bacanga, São Luís (MA). XVII Encontro de Geógrafos. São Luís, Maranhão, Brasil. 